\title{
Investigating the Possibility of Using Mobile Phones for Science Teaching and Learning: Is It a Viable Option for Sri Lanka?
}

\author{
T.M.S.S.K. Yatigammana Ekanayake, J.M. Wishart \\ University of Bristol, United Kingdom
}

\begin{abstract}
This research was motivated by previous research which found that mobile phones could be used to enhance the effectiveness of science teaching and learning. The aim of this study is to explore the possibilities of using mobile phones to teach science in Sri Lankan schools where ICT resources are inadequate or unavailable. First the current situation on the use of ICT and the availability of mobile phones was explored. Next the teachers' readiness to use mobile phone in science teaching and learning was investigated. The methodological approach used in this research was mixed methods. The data were collected using documents, survey and follow-up interviews. The sample was secondary level science teachers of one province in Sri Lanka. Data were analysed using SPSS statistical package and thematic analysis. Results concluded that the available ICT resources in schools are inadequate to teach science and that the mobile phones are widely spread and cheaper than computers. The teachers are competent in using most of the functions of mobile phones and teachers' attitudes towards the use of mobile phones in science teaching are positive. The outcomes of the research suggest that the possibility of using the mobile phones in science teaching in Sri Lankan schools is high.
\end{abstract}

\section{Introduction}

Science teaching is difficult and complex when compared to other subjects [0]. According to [0], science involves abstraction, difficult ideas and theoretical entities that cannot be seen or handled. Furthermore, in [0] it is claimed that science is not an archive of facts but complex sets of theories, laws and so forth that we use to model the world. These complexities in science demand new teaching methods that support students in grasping complex ideas and concepts. Recent literature based on the use of ICT in science teaching and learning provide evidence on the potential of ICT in science teaching and learning [0][0][0]. Explaining this further, in [0] it is noted that opportunities provided by ICT benefit the teaching of science by promoting the student's understanding of abstract concepts, enabling students to relate science to their own and real world experiences and facilitate, data collection and presentation.

The study reported in this paper investigates the possibility of using mobile phones for science teaching and learning. The motivation for this work was from the fact that even though science teachers in Sri Lanka recognised the opportunities provided by ICT to enhance science teaching, teachers still use traditional teaching methods to teach science due to the lack of resources and the cost involved. Due to high penetration of mobile phones and as they offer a range of potential for science teaching, it has been recognised that it is viable to use mobile phones for science teaching in Sri Lankan schools. Therefore, in this paper, the possibilities of using mobile phones for science teaching in Sri Lanka are investigated.

The paper is organised as follows. In section 2, the literature survey on science teaching and learning and the use of ICT and mobile phones for science teaching and learning is discussed. Next the current situation in ICT and mobile phones in Sri Lanka is discussed. The findings from a survey and follow up interviews that were carried out in Sri Lanka to investigate whether secondary level science teachers are prepared to make use of the opportunities provided by mobile phones in teaching science are presented afterwards. Finally, any barriers that hinder the widespread use of mobile phones in science teaching and learning in schools are discussed.

\section{The literature review}

\subsection{Why science teaching and learning is difficult?}

Science education consists of two components: the content and the processes [8]. Elaborating on this further, in [9] it is stated that the content of science includes facts, laws and theories, and the processes of science consist of observing, measuring, recording, processing data, hypothesising, communicating and discussing, trying things out, investigating, handling things, watching and monitoring. Considering the teaching of science, in [10] it is claimed that in order to support students' science learning, two interrelated areas, namely understanding of content and understanding of processes should be developed. As a strategy in [9], it is suggested that this can be done by teaching the content of science alongside its processes. In [4], [5] and [6] it is recognised that ICT has the potential to support the teaching and learning of both science content and process. 


\subsection{How ICT could support science teaching and learning?}

ICT can help in learning the content of science using information sources such as the internet and materials on CD-ROM as well as processes of science such as measuring, recording and processing data, hypothesising and communicating [4]. In the report on 'Literature review in science education and the role of ICT' [11], the use of ICT, in the form of tools for data capture, processing and interpretation; multimedia software; information systems; publishing and presentation tools; and digital recording equipment that support school science teaching and learning is discussed. Furthermore, in [2] it is stated that simulation, multimedia applications, data-logging, spreadsheets, databases and the internet are important. Even though the above literature discusses the potential of ICT for developing science content and process, in [5] it is argued that ICT cannot replace the conventional teaching and learning approach, but in a chapter of the book entitled 'Aspects of secondary science' [12], it is stated that instead ICT is a tool to enhance and improve the effectiveness of science teaching and learning.

\subsection{How mobile phones could support science teaching and learning?}

Mobile devices such as mobile phones, smart phones, palmtops and handheld computers (personal digital assistants (PDA) and tablet PCs) add an extra dimension to the use of technology in teaching and learning [13]. In [14] and [15], it is concluded that mobility and portability provided by these devices have the potential for making access to information and interaction more effective. Considering the educational potential of mobile devices, in [16] it is stated that mobile devices add new educational opportunities because they are personal, portable and permit new forms of interactions among all involved in the learning process and their respective surrounding environment. Identification of a range of possibilities provided by mobile devices for teaching and learning has led to the emergence of a new concept called mobile learning (m-learning) during the last few decades. Amongst mobile devices, PDAs and mobile phones are the most commonly used technologies for m-learning. Besides in [17] it is stated that mobile phones have been considered as the most successful technology for m-learning. Furthermore, in [18] the author goes so far as to state that present-day mobile phones are complete multimedia centres that combine the capabilities of a still camera, a video camera, a personal organizer and a web browser in one device. Emphasising the possibilities of introducing mobile phone as a learning tool, in [19] it is stated that the learning curve of the mobile phone is very short and therefore it is easier to begin to use mobile phones and PDAs rather than laptop computers. One reason they point out is that the mobile phone menus are designed with icons and text descriptions that help anyone to identify the functions easily. Comparing the cost, the reference [20] notes that many mobile devices are cheaper to purchase than desktop computers and laptops, and that introducing the mobile phone as a low-cost teaching and learning tool is possible. Further he also states that mobile devices require less technical support than computers and laptops.

When considering science learning, the mobile phones allow the learner to learn autonomously [21], collaboratively [22] and also provide opportunities to conduct learning experiences outside the teachermanaged classroom [23] by expanding learning beyond the four walls of the classroom and thus allowing interactions in the real world including new interactions to be brought into the classroom [24].

The implementation of m-learning opportunities in science lessons are now reported in the literature. For example, [25] report a study where the students used the mobile phone's image capture function in a secondary level science lesson in the UK. The mobile phone's camera was used to capture evidence of experiments on plant growth as collaborative work. Findings show that the images taken during experiments helped students to accurately record physical observations and thus enabled them to validate the experiment afterwards. According to the comments of students and the teacher, this physical record (images) provided a chance for both students and the teacher to retrieve material if necessary and reflect on it over time. Furthermore, students appreciated the fact that they could upload the images onto the computer and post them on their portfolios.

Another potential of the mobile phone is its image capture function allowing teachers and/or students to bring 'the outside world' into the classroom during a science lesson [26]. According to the findings of this study, the mobile phone camera was used to support the teacher during the different stages of a science lesson including planning, implementing and reviewing. The phones themselves helped students to learn science effectively by enabling collaborative and authentic learning opportunities. In addition to this, in [27] a study is reported where students used the mobile phone video facility to record the deflection of a galvanometer in a secondary level science lesson. According to the authors, the mobile phones' video camera helped students to capture a fleeting (observation) event which could otherwise be missed. This enabled the students to view their observations repeatedly and share them with their peers. Furthermore, [28] discuss the use of the mobile phone to connect the lesson content to 
students' prior knowledge and correct misconceptions during science lessons.

The use of mobile phones to support science teaching and learning outside the classroom is also becoming more common. A multimedia m-learning application for biology lessons is proposed in [29]. In this study, the students recognised a plant following a Wireless Markup Language (WML) text description and MMS provided by the teacher. While searching for the plant, the students communicated with their peers and the teacher by exchanging pictures and sending MMS.

A sensor system for environmental education was developed using mobile phones as a means of enhancing learner participation and motivation. A participatory design approach was used to develop the sensor system. In this study the students collected a range of sensor data using probes and mobile phones (connected to a datalogger via Bluetooth).

Earlier in [30] a study was reported where probes connected to handheld computers were used to determine the water quality in a river. In this study, each student took a measurement using a probe at different points along the streambed. The students combined their data by beaming it to a common personal computer. Then they used their handheld devices to analyse this data and prepared graphs of combined data sets. This m-learning opportunity allowed students to focus on interpretation rather than the tedious process of recording and plotting data. Further, collecting and sharing of data led to inquiry based scientific practice both inside and outside the classroom.

Emphasising the children's understanding of contextual information according to the circumstances in which data was collected, in [31] a second study was reported where school students (aged 13-15) used mobile sensors to collect scientific data in their local areas. These students were provided with a datalogger with a selection of environmental sensors (probes) and a mobile phone with sound sensor software connected via Bluetooth to a GPS unit. Students took turns to take a set of data collection equipment with them on their journeys from home to school. They collected data on carbon monoxide (CO) levels, sound and temperature. The students also used mobile phone video and image capture to produce a 'snapshot' of the conditions they had experienced. On their return to the classroom, the data were downloaded onto a personal computer. This activity allowed students to collect, visualise and discuss their own scientific data more effectively than was customary.

Further, by briefing the studies on the literature where the mobile devices are used for data logging in schools in [32] it is suggests that handheld computers, PDAs and similar mobile devices can be seen to offer contextualized, constructive, authentic opportunities for science learning.

\section{ICT resources and their use in Sri Lanka}

In terms of technology supported learning, it is fair to say that Sri Lanka lags behind many countries in the world. The Sri Lankan Government is exerting more effort to establish computer laboratories in schools and train teachers in ICT based teaching and learning. The Ministry of Education (MOE) has established 3012 computer labs in 9714 schools throughout the country under different projects [33]. In addition to computer labs received from the MOE, several schools have obtained computers through donations made by parents and former students. However, the current computer to student ratio is about 1:130 [33]. It was found (from the research study reported here) that these computer labs are mainly used for teaching ICT as a subject and only occasionally expose students to various CD-ROM based science teaching materials such as those provided by the MOE. It is unlikely that the Sri Lankan schools will be up-to-date and sufficient in ICT resources in the near future due to the current economic climate and the scarcity of basic infrastructure facilities such as electricity in some schools. Also the rapid development of ICT resources and the widening digital divide makes it virtually impossible to keep pace with the current state-of-the-art.

When looking at the ICT use in the Sri Lankan context, it was recognised that due to restrictions imposed on available computer facilities for science teaching in schools and the non availability of ICT equipment that can be taken into the classroom or outside (video cameras, laptops), the possibilities of providing authentic learning experiences are restricted. For example, some teacher trainees (including a student registered for an MSc Degree in the University where I taught) said that even though they learnt and practiced the applications of ICT in science teaching and learning, they could not apply these in their schools due to the unavailability of the ICT resources. This was further verified during one of the Science Workshops that I carried out in July 2009 for science teachers from one of the educational zones. Nine teachers out of fifty raised their hands saying that they did not have the resources in their schools to use ICT in science teaching and learning.

\section{Possibility of using mobile phones for science teaching in Sri Lanka}

Inadequate ICT resources and resources that could be taken outside the classroom, in Sri Lanka have prevented harnessing different opportunities provided by ICT for science teaching and learning. However according to the literature (discussed in 
section 2.3) mobile phones are cheap and provide many functions offered by computers, video camera and still camera. Therefore, it is worth investigating the possibility of using mobile phones for science teaching and learning in Sri Lanka. This will need assessment of available resource, teachers' competence and their attitudes and any barriers that obstruct implementation.

\subsection{What is the availability of mobile phones in Sri Lanka?}

The mobile phone will be an ideal tool for developing technology supported learning in schools for many reasons. Some of these include:

a) The mobile phones are cheap and widely spread in Sri Lanka and users, especially teenagers, are well acquainted with their functions.

b) The penetration level of mobile phones in Sri Lanka was $70 \%$ by the end of 2009. Furthermore, it has not only increased exponentially as shown in Figure 1, but also the penetration has become much higher than that of computers.

c) Most of Sri Lanka is covered by mobile phone networks.

d) Mobile phones could be used even in schools where electricity is not available as phones can be charged using a battery.

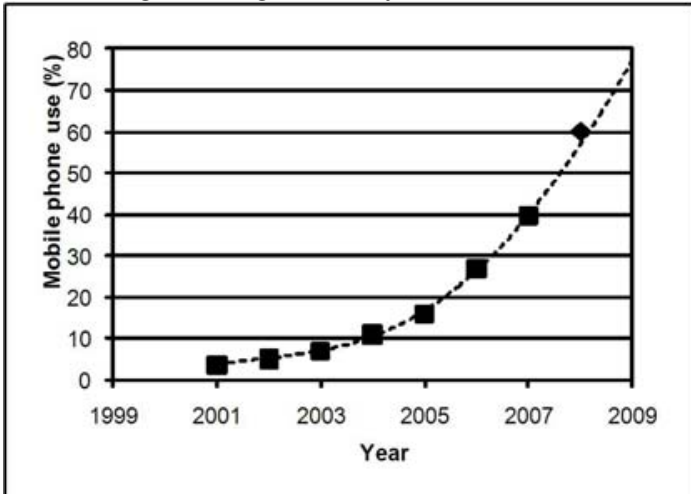

Figure 1. The penetration level of mobile phones in Sri Lanka [34]

If mobile phones can be used successfully for science teaching and learning processes, they will become a popular and effective teaching tool in Sri Lanka. It will allow students to transcend barriers imposed by the four walls of the classroom. Students will be able to use mobile phones to gather information, to bring the real world into the classroom and to take the classroom into the real world.

\subsection{Are Sri Lankan teachers ready to use the mobile phone?}

First a survey was carried out in order to explore whether teachers are competent enough to use mobile phone and their attitudes towards the use of mobile phones for science teaching and learning. The survey sample comprised of science teachers who teach science at secondary level (from grade 6 -11) in $1 \mathrm{AB}, 1 \mathrm{C}$ and 2 type schools1 in the Central Province of Sri Lanka. The survey questionnaire was administered to 200 participants to minimise the effects that may arise due to a low response rate. To select the sample, the stratified and systematic sampling methods were used, which helped to obtain a more representative sample.

Fifteen teachers were interviewed after the results of the survey questionnaires were analysed. This sample was selected purposively based on their responses to the survey questionnaire which might have opened up some interesting lines of inquiry, or their use of ICT in teaching and competency in using the mobile phone, and also included the ease of access to the interviewees themselves. Out of fifteen, eleven interviewees were female. The majority of interviewees $(2 / 3)$ had more than 11 years of teaching experience.

4.2.1 Data collection and analysis. As mentioned before, for this study the data were collected using the mixed methods approach [35] using a postal survey questionnaire and a follow-up semi-structured interviews. The aim of using these methods was to obtain an overall picture of m-learning readiness of Sri Lankan science teachers. The survey questionnaire was used not only to obtain information relating to the teachers' competence of using mobile phones but also to assess their use of existing technology in science teaching. Some of the sections included in the questionnaire were (a) Sri Lankan science teachers' views on the use of ICT in teaching and learning, (b) their use of existing ICT facilities in teaching and learning science, (c) their competence in using mobile phone functions and (d) their opinions on using mobile phone together with existing ICT facilities in the process of teaching and learning science. The survey used forced choice questions with 4 point Likert Scale type responses and included an open ended question asking for any other comments or suggestions about using mobile phones in science teaching and learning. However the findings relating to the use of mobile phones were only used in this paper.

The survey data were analysed using the SPSS statistical package and the interview data was analysed using thematic analysis techniques.

\footnotetext{
${ }^{1}$ There are four types of schools in Sri Lanka education system. Type $1 \mathrm{AB}$ schools (with classes up to grade 13 including A' Level science stream), Type 1C schools with classes up to grade 13 but without A' Level science stream, Type 2 schools with classes up to grade 11 and Type 3 schools with classes up to grade 5 .
} 
4.2.2 Teachers' competence. The postal survey was completed by 152 science teachers (response rate $76 \%$ ) in the Central Province of Sri Lanka. From the responses approximately $2 / 3$ of the sample was female. The majority of respondents $(73.7 \%)$ had substantial teaching experience (6 or more years) and $2.6 \%$ of respondents had less than a year's experience.

The survey explored respondents' experience of the use of mobile phone and their attitudes towards the use of mobile phones in the process of teaching and learning. The respondents' responses on their level of competence in the use of mobile phone functions are shown in Figure 2.

Except for the use of Multimedia Messaging Service (MMS), internet browsing and videoing, around two-thirds or more of the respondents had used the other functions of the mobile phones. This was identified as a significant finding as it indicates that the Sri Lankan teachers exhibit competence in a variety of uses of mobile phones and by providing appropriate professional training, it is anticipated that it is easy to improve their competence to use all the functions of mobile phones.

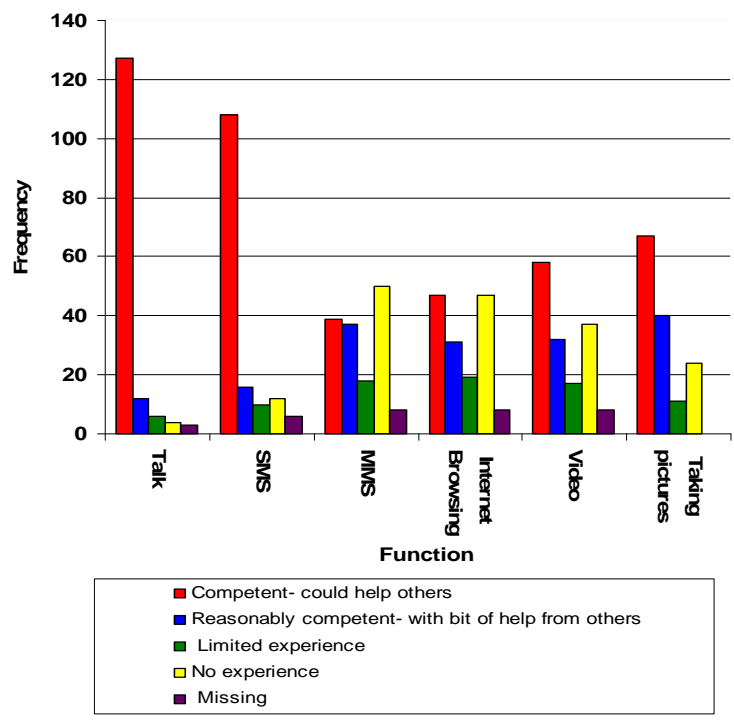

Figure 2. Respondents' competence in the use of mobile phone functions

4.2.3 Teachers' attitudes. In order to assess teachers' attitudes, two types of statements were included in the survey questionnaire. They were the statements which are positive towards the use of mobile phones and the statements which bring important information that needs to be considered during the introduction of mobile phones into science teaching and learning.
Table 1. Participants perspectives in use of mobile phones

\begin{tabular}{|c|c|c|}
\hline Opinion statement & 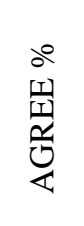 & 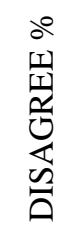 \\
\hline $\begin{array}{l}\text { As a widely available tool, it is a } \\
\text { practical thought to use mobile } \\
\text { phones in the process of teaching and } \\
\text { learning science }\end{array}$ & $64 \%$ & $36 \%$ \\
\hline $\begin{array}{l}\text { The various functions of mobile } \\
\text { phone such as text, speech, video, } \\
\text { taking pictures could be used to plan } \\
\text { my lessons }\end{array}$ & 74.3 & 23.0 \\
\hline $\begin{array}{l}\text { The portability of mobile phone } \\
\text { enables science teaching and learning } \\
\text { both inside and outside the classroom }\end{array}$ & 78.3 & 17.8 \\
\hline $\begin{array}{l}\text { Mobile phone is a cheaper alternative } \\
\text { to video and the still camera }\end{array}$ & 91.4 & 5.9 \\
\hline $\begin{array}{l}\text { Generally students are familiar with } \\
\text { functions such as text, speech and } \\
\text { taking pictures of mobile phones }\end{array}$ & 81.6 & 15.8 \\
\hline
\end{tabular}

The survey findings show (in Table 1) that the teachers had positive attitudes towards the possible use of mobile phones in science teaching and learning. For example, 77 out of 152 (64\%) respondents agreed with the statement that 'as a widely available tool, it is practical to use the mobile phones in the process of science teaching and learning'. In addition to this, teachers stated their positive views as responses to the open-ended questions in the survey. For example - for the question, 'your opinion in using mobile phones for teaching and learning science'; two teachers pointed out the possibility of using mobile phones in schools where ICT facilities are not available. Thus these responses not only indicate the teachers' acceptance of the use of mobile phones in science teaching in Sri Lanka and further thinking about its use to overcome the inadequacy of ICT resources in schools.

Furthermore, $74.3 \%$ of respondents agreed with the statement relating to the potential of mobile phone functions in lesson planning ('the various functions of the mobile phone such as text, speech, video, taking pictures could be used in planning my lessons'). Moreover, for the open-ended question in the survey, 9 respondents out of 152 said that they had used their mobile phone in science teaching. Amongst them, nine had used the image function of the mobile phone, whereas only four of them had used video function and one respondent had used the sound recording function of the mobile phones during their teaching and learning of science. The 
following excerpts from the interviewees further supported this:

"I have used my phone to show some pictures of plants. I downloaded them using the internet facility of my mobile phone and showed them to students during the lesson. The small screen did not create any problems as the number of students in the classes of my school is less than $20 "$.

(Interview transcript 5 - 2009/07/06)

\begin{abstract}
"I have my mobile phone. Last year there was a flower in our home garden called "Kidaran". When I saw that I took a photograph. Because I know that most of the pupils haven't seen that because it is not a very common flower. So later in one of the lessons [...] sorry I do not remember the name of the lesson, I showed the picture of that flower to my pupils. Not to all the students, as the screen is too small, but for some of them who were interested. And once when I went to Kirinda I saw some "Ulva" and got a photograph and used those pictures during the lesson in the school. That means that ...rare things that accidentally we come across in our day to day life ... I mean if we can get photos or videoed and use them in our teaching appropriately.”
\end{abstract}

Interview transcript 3 (2008/12/22)

Moreover, $78.4 \%$ of the survey respondents agreed with the statement that 'the portability of the mobile phone enables science teaching and learning inside and outside the classroom', and thus supporting the possibility of using mobile phones for science teaching whenever required.

"Mobile phones are very common and cheap today. It is easier to buy a mobile phone than a computer. We can easily take it to the places where we want. As teachers we can take it to the classroom but it is impossible to take a computer to the classroom."

(Interview 6)

Teachers also had recognized the possibility of using a mobile phone instead of a still or video camera. For instance $91.4 \%$ of respondents agreed with the statement 'the mobile phone is a cheaper alternative to the video and the still camera'.

One teacher said:

"I think the mobile phone will be really useful when we do field work as you mentioned in your survey, to bring the outside world to the classroom,....because we do not have a digital camera or video camera in our school."

(Interview 10)

On the use of the mobile phones in science teaching and learning, $81.6 \%$ of teachers agreed with the statement that 'generally students are familiar with functions such as text, speech and taking pictures from mobile phones'. In addition to this, during the teachers' interviews, they described incidents that they had come across where their students had used the mobile phone camera to capture some images relevant to science learning, during school trips. Therefore, according to findings teachers had a positive attitude towards the students' competence of using mobile phones in science learning. This was further supported by the following excerpt from the interviews:

"Most of the teachers as well as students have their own mobile phones and they are familiar with most of the functions. But they are not used in learning or teaching purposes. For an example in our school, which is a private school, there are 25 students in my class. About 18 of them have good mobile phones. They all know how to find information by browsing the internet, send emails, text and all. So this will be a good starting point for using mobile phones in education".

(Interview transcript 4 - 2009/07/07)

"If there is a possibility to use mobile phones in teaching and learning in the school, which would be very useful because mobile phones are cheaper than computers and therefore a school can buy mobile phones instead of computers and the children, have better knowledge than us to use the mobile phone. For example I have learnt a number of ways of using the functions of my own mobile phone from my daughters who are 10 and 12 years old".

(Interview 1)

\subsection{What are the barriers for the use of mobile phones?}

Table 2 shows the questions included to assess the problems associated with the use of the mobile phone in teaching and learning science.

Table 2. The problems associated with the use of mobile phones

\begin{tabular}{|c|c|c|}
\hline Opinion & 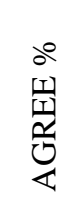 & 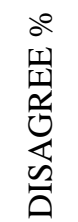 \\
\hline $\begin{array}{l}\text { As the mobile phone displays are } \\
\text { small, they may not be useful for } \\
\text { teaching. }\end{array}$ & 80.9 & 13.8 \\
\hline $\begin{array}{l}\text { The use of mobile phones in teaching } \\
\text { and learning could hinder classroom } \\
\text { discipline. }\end{array}$ & 72.4 & 25.0 \\
\hline $\begin{array}{l}\text { The cost associated with mobile } \\
\text { phone use will be a problem. }\end{array}$ & 84.2 & 13.8 \\
\hline $\begin{array}{l}\text { Mobile phones could create health } \\
\text { hazards. }\end{array}$ & 70.4 & 23.7 \\
\hline
\end{tabular}


As the main barrier the respondents highlighted the cost of introducing mobile phones in science teaching and learning; $84.2 \%$ of the respondents agreed with the statement that the cost associated with mobile phone use will be a problem. Two respondents noted as responses to the open ended question,

a) Even though the use of mobile phones in science teaching and learning is useful and timely, paying bills would be a big problem.

b) Even though the possibility of the use of mobile phones in Sri Lanka is high, expenses need to be borne by us and the students.

However during the interviews one participant suggested an alternative way of managing the cost as:

"All the students do not have mobile phones and school can't afford to buy mobile phones for all the students and pay the bills. However, if a school... I mean a lab can have a certain number of mobile phones like computers or other equipment in the lab.... then teacher can use them when implementing a lesson."

(Interview 2)

The possible disciplinary issues were also mentioned as a challenge, where $72.4 \%$ of the respondents in the sample responded as 'strongly agree' or 'agree' with the statement: "the use of mobile phone in teaching and learning could hinder classroom discipline”. However during the interviews teachers did not directly state this, instead their view was that mobile phone can be used in the process of school teaching and learning under the teacher's control. The following excerpts give clear evidence for this:

"It is good. But it should be under teacher's control. That means ...... students can use mobile phones...mmm....if the teacher asks pupils to use them during the lesson or if pupils get teacher's permission and when the teacher feels that pupils' request is appropriate and it is alright. But if they ask to use mobile phone to do something that will disturb the lesson, I won't allow it. You know what I mean....”

(Interview 2)

"I think the school disciplinary problems arise if the teacher does not have necessary skills like classroom management skills and leadership skills.”

(Interview 4)

Furthermore, $80.9 \%$ strongly agreed or agree with the statement that "mobile phone displays are small and may not be useful for teaching". Teachers' inadequate training to use mobile phone functions alone or by integration with other ICT recourses was also pointed out as an issue in both survey and interviews. One interviewee stated her difficulties as follows:
"I have used the functions such as taking photos and videoing in the process of teaching and learning. Even though my phone has got these functions, I haven't got a cable to transfer them to a PC and... actually I do not know how to upload them. If I have a code and the skill or knowledge of transferring them to the PC it will be really useful. Yes it is a good step".

(Interview 7)

\section{Conclusions}

This study investigate the possibilities of using mobile phones for science teaching and learning in Sri Lanka by considering the availability of mobile phones, readiness of Sri Lankan teachers to use mobile phones in science teaching and learning and the possible barriers that can be encountered when introducing mobile phones for teaching and learning of science in schools.

The high penetration and much lower price of mobile phones in Sri Lanka compared to computers are identified as a fact in supporting the use of mobile phones in science teaching and learning. Furthermore, due to the wide coverage of mobile phone networks, supporting the use of mobile phones in schools situated in remote areas where the other ICT resources are difficult to make available.

The findings of the survey and interviews revealed that teachers are competent to use most of the mobile phones functions and others can be developed with a bit of help. This would not be a difficult task as the learning curve of mobile phone is shorter than the computers as suggested by Csete et al. (2004). Therefore teachers' competence is also a positive finding of this study, since it depicts that by providing an appropriate professional training on the use of mobile phone in teaching and learning the teachers would be ready to use mobile phones in science teaching.

The findings of the survey and interview show that the teachers' attitudes towards the use of mobile phones in science teaching and learning seem to be positive due to several reasons. Firstly, the teachers' acceptance of the mobile phone (which are widely available in Sri Lanka) as a science teaching tool is very important. This indicates their understanding of mobile phone as a tool that has educational potential. This was elaborated further from their interview with experts who explained that teachers' were able to use of some functions of their own mobile phones in science teaching even though the mobile phone had not been introduced as an educational tool to the education system of Sri Lankan.

Secondly as pointed out by (Ekanayake \& Wishart,2010a), the survey and interview data indicate the teachers' understanding of the potential of the camera function of mobile phone in order to bring the outside world into the classroom and make student science learning effective. Moreover, their 
survey responses (91.4\% were agreed ) and interview experts demonstrate the teachers' recognition of using mobile phone camera and video camera as an substitute to video and still cameras.

Teachers' recognition of the students' competence (81.6\%) of using mobile phones can be seen as another favorable finding of this investigation. This is because it reveals the possibility of using mobile phone in learning activities in science where the teacher can use different teaching approaches to teach science which was identified as a complex process (Alsop, 2005). In addition the teachers' recommendation of using mobile phones for science teaching in the schools where the computers are unavailable, is also depicted their confidence in the educational potential of mobile phones. However, this can be considered as an important idea since the mobile phone can be purchased and used as a teaching and learning tool in remote schools at a low initial cost as suggested by Dawson (2007).

The survey findings show the cost, disciplinary problems and small screen size of the mobile phone as the main barriers. Interestingly, interview excerpts elaborate on the teachers' acceptance of the possible controls on the first two barriers. Moreover, different recommendations of teachers to overcome barriers indirectly show teachers' positive attitude towards the use of mobile phones in science teaching and learning.

According to the above findings it is clear that the availability of mobile phones and also teachers' readiness to use mobile phones show the possibility of introducing the mobile phone as viable option to science teaching and learning in Sri Lanka.

The main weakness of this study was the selection of teacher sample from one province in Sri Lanka. Furthermore, these results are based on limited samples of lessons in Sri Lanka and more work should be carried out before making broad generalisations.

\section{Acknowledgements}

The authors wish to thank the University of Peradeniya, Sri Lanka for supporting this activity and the teachers who participated in this study.

\section{References}

[1] Alsop, S., Motivational belief and classroom contextual factors: exploring affect in accounts of exemplary practice., in Analysing exemplary science teaching, S. Alsop, L. Bencze, and E. Perdretti, Editors. 2005, Open University Press: Berkshire. p. 146-159.

[2] Wellington, J., Multimedia in science teaching in Teaching secondary science with ICT R. Barton, Editor. 2004: Berkshire. p. 87-102.
[3] Taber, K.S., Conceptual development, in Analysing exemplary science teaching, S. Alsop, L. Bencze, and E. Pedretti, Editors. 2005, Open University Press: Berkshire. p. 127-136.

[4] Wellington, J., Using ICT in teching and learning science, in Mediating science learning through information and communications technology, R. Holliman and E. Scanlon, Editors. 2004, RoutledgeFalmer: London. p. 51-78.

[5] Barton, R., Closing remarks, in Teaching secondary science with ICT, R. Barton, Editor. 2004, Open university Press: Berkshire. p. 155-158.

[6] La Velle, B., L.M. McFarlane, and A.R. Brawn, Knowledge Transformation Through ICT in Science Education: A Case Study in Teacher Driven Curriculum Development. British Journal of Educational Technology, 2003. 34(2): p. 183-200.

[7] Webb, M.E., Affordances of ICT in Science Learning: Implications for an Integrated Pedagogy, International Journal of Science Education, 2005. 27 ( 6): p. 705 - 735

[8] Newton, D.P., Making science education relevant, ed. T. Marjoram. 1988, London: Kogan Page LtD.

[9] Wellington, J. and G. Ireson, Science learning, science teaching. 2008, Oxon: Routledge.

[10]Braund, M., Starting science again? Making progress in science learning. 2008, London: Sage.

[11] Osborne, J. and S. Hennessy, Literature Review in Science education and the role of ICT: Promise, Problems, and Future Directions, in Future lab. 2003.

[12] Boohan, R., ICTand communication, in Aspects of teaching secondary science, S. Amos and R. Boohan, Editors. 2002, RoutledgeFalmer: London. p. 211-224.

[13] Kukulska-Hulme, A., Introduction, in mobile LEARNING :a handbook for educators and trainers, A. Kukulska-Hulme and J. Traxler, Editors. 2005, Routledge: Oxon. p. 1-6.

[14]Moura, A. and A.A. Carvalho. Mobile learning: teaching and learning with mobile phones and Podcasts. in Eighth IEEE International Conference on Advanced Learning Technologies. 2008. Portugal.

[15] Scanlon, E., A. Jones, and J. Waycott, Mobile Technologies: Prospects for their Use in Learning in Informal Science Settings. Journal of Interactive Media in Education, 2005. 25.

[16]Arrigo, M. and G. Ciprì, Mobile Learning for All. Journal of the Research Center for Educational Technology, 2010. 6(1).

[17] Markett, C., et al., Using short message service to encourage interactivity in the classroom. Computers \& Education, 2006. 46(1): p. 280-293. 
[18] Marriott, M., Use this phone to find a date.-Or see video. Or even talk, in New York Times. 2005.

[19] Csete, J., Y.H. Wong, and D. Vogel. Mobile devices in and out of the classroom. in World Conference on Educational Multimedia, Hypermedia and Telecommunications 2004. Switzerland.

[20]Dawson, D., Handheld technologies for mobile learning 2007, London: latimer Trend.

[21] Callum, K.M. and Kinshuk. Mobile Technology in Facilitating Learning Goals. in mLearn 2006 2006. Banff, Canada.

[22] Eliasson, J., et al. Get the bees away from the hive: balancing visual focus on devices in mobile learning. in IADIS Mobile learning 2010. 2010. Porto, Potugal.

[23] Corbeil, J.R. and M.E. Valdes-Corbeil, Are You Ready for Mobile Learning? Educause Quarterly online Journal, 2007. 30(2): p. 51-58.

[24] van 't Hooft, M. and K. Swan, Ubiquitous computing in education: Invisible technology, visible impact. 2007, Mahwah: Erlbaum.

[25] Hartnell-Young, E. and N. Heym, How mobile phones help learning in secondary schools, in Becta 2008, Learning Sciences Research Institute, University of Nottingham: Nottingham.

[26] Ekanayake, T.M.S.S.K. and J.M. Wishart. Identifying the potential of mobile phone cameras in science teaching and learning: a case study undertaken in Sri Lanka. in Mobile learning 2010, IADIS International conference. 2010. Porto, Portugal.

[27] Ekanayake, T.M.S.S.K. and J.M. Wishart. Use of video function of mobile phones for science teaching. in Learning future festival Online. 2010. University of Leicester.

[28] Ekanayake, T.M.S.S.K. and J.M. Wishart. Using mobile phones in implementing science lessons: teachers' pedagogical practices. in MLearn 2010. 2010. Malta

[29]Benta, K. and M. Cremene. Multimedia m-learning using mobile phones. in MLEARN. 2004. London.

[30] Vahey, P. and V. Crawford, Palm Education Pioneers Program: Final evaluation report. 2002, SRI International: Menlo Park.

[31] Woodgate, D., et al. Mobile Learning in Context: School Science Data Collection as Legitimate Peripheral Participation? in Mlearn 2008. Wolverhampton.

[32] Wishart, J., The role of information and communications technology, in How Science Works: Exploring Effective Pedagogy and Practice R. Toplis, Editor. 2011, Routledge: Abingodon, Oxon. p. 118-132.

[33] Gunadasa, G.M.N. ICT in Education Policies in Sri Lanka: Challenges and Opportunities. in e-Global Leaders Conference 2007. Seoul, Korea.
[34] Samarajiva, R. Mobile penetration in Sri Lanka 2008 [cited 2010 January 3rd]; Available from: http://lirneasia.net/wpcontent/uploads/2008/10/sarvodaya26oct08.ppt.

[35] Cresswell, J.W. and V.L.P. Clark, Designing and conducting Mixed methods research. 2007, Thousand Oaks: Sage. 